\title{
Development of air tightness prediction method of masonry walls
}

\author{
Valdemaras Geležiūnas $^{1, *}$, Karolis Banionis ${ }^{1}$, Valdas Paukštys ${ }^{1}$, and Jurga Kumžienè ${ }^{1}$ \\ ${ }^{1}$ Kaunas University of Technology, Institute of Architecture and Construction, Tunelio st. 60, Kaunas, Lithuania
}

\begin{abstract}
Recently, the construction of external walls of various blocks, which are externally insulated with mineral wool thermal insulation layer, with ventilated air gap and external finishing (ventilated wall structures) is becoming popular for public and office buildings. These blocks are used without internal rendering because they have a good interior surface, stable dimensions, and various filling of masonry joints provide an attractive architectural appearance. This reduces the cost and duration of construction work, however, problems with airtightness of such walls often occur. The air can penetrate through blocks or their joints, and the thermal insulation and wind protection layer does not usually provide the required air tightness of the wall. Currently, there are no standard methods to predict the air tightness of such wall, in practice, samples of particular walls are produced and their air permeability is measured at the laboratories. This is a costly job, which is only suitable for a combination of particular building materials. For the broader use of results of laboratory air permeability measurements, a methodology has been developed to predict the air permeability of block masonry walls using experimentally determined air flow resistances of the individual layers. The masonry from blocks, made of ceramic, expanded clay and aerated concrete with various joints, were used for the research; mineral wool boards of various air permeability were used for thermal insulation and wind protection layer. After measuring the air resistance of masonry units, thermal insulation and wind protection boards, the air flow resistances of the walls of different construction were calculated. The comparison of calculated and measured air permeability of wall samples showed that in cases where the nature of air movement (laminar to turbulent) through a single material remains similar with the nature of air movement through the product incorporated in the structure, the calculation and measurement data differ no more than $12-15 \%$. In structures with building products with very different air permeability properties, especially at high thicknesses of air permeable thermal insulation products, air movement parameters change occurs and calculated and measured results have larger differences.
\end{abstract}

\section{Introduction}

Building airtightness measurements has become an important part of modern building evaluation process. These measurements help to evaluate the quality of the building and determines airtightness level of the building which helps to reduce the energy consumption of the building, for the purposes of directive 2010/31/EU. Building energy performance calculations are accurate only when the building airtightness is evaluated correctly [1]. Researches are trying to develop airtightness prediction methods but none of them could replace measurements [2].

Final air permeability measurements of whole building are being done after the building's construction phase is done. Repairing works could result a high amount of money and time if any leakages are found after this phase. Therefore, it is important to know constructions which can guarantee the minimal requirement of building airtightness. For this reason, prediction of air permeability of entire structure of the building could be useful for design of air tightness of whole building, preserving from mistakes, therefore, saving time and money.

As mentioned by M. Prignon et al. (2017) [3], from theoretical, empirical, building characteristic and single component building airtightness prediction models, the latter is the most promising, although large database of laboratory air permeability testing results for different types of constructions should be created. In this kind of database one of the most important matters would be to categorize the constructions by type and uniform metrics, so that usage of this prediction tool would be as much practical as it can be.

Air leakage paths could occur through the construction unit or through joints between construction elements and with other constructions as well. For example, investigating air permeability through wall of lightweight aerated concrete blocks with installed chimneys [4] it was found, that air leakage through this connection reduces airtightness of whole building. Surface rendering in this case creates a continuous air tightness of this structure.

\footnotetext{
* Corresponding author: valdemaras.geleziunas@ktu.lt
} 
There is also other research about airtightness of different constructions. J. Hallik et al. (2019) investigated air leakage through various timber joints filled with three different polyurethane foams [5]. Results showed that surface properties and thickness of the joint had the biggest influence on air permeability. There were no significant changes in results by changing the type of the foam.

T. Kalamees et al. (2017) measured air leakage levels for eight joints which were used for different tightening solutions in the prefabricated timber-framed building envelope [6]. The structures giving worst air permeability were identified and a big difference between measurements results in laboratory and in situs was fixed. Workmanship quality and created air leakage places (plumbing penetrations, electrical service penetrations etc) could be identified as main reasons of this difference. J. Langmans et al. (2016) investigated the impact of climatic conditions on the airtightness of typical taped joints [7]. In this case, air barrier was realized at the exterior. Results showed that temperature, rain and frost cycles had impact on air permeability of taped air barrier, but the increase was still very small.

Research on air permeability of different constructions helps to find out ways of air movement through different parts of building envelope. In order to create airtightness prediction model H. Krstic et al. (2014) validated neural network model using in situ measurements data from Croatia [8] and later on Serbia [9]. After that, he improved his method by adding buildings airtightness measurements results of similar constructions from Poland [10]. It was proven that this kind of prediction model has potential to predict airtightness for future buildings. Although problem of this model is insufficiency of other types of buildings constructions. Prediction is only suitable for similar location, climatic zone and constitution of building construction. Therefore, as it can be seen from literature review, one of the most promising building airtightness prediction tool is building component air permeability model. [3]

Air permeability values of every building material or product intended to be integrated into the building envelope shall be included in data base of building airtightness prediction tool. Currently only windows and doors has requirements for air permeability testing and declaration of air leakage values for air tightness calculation purposes. Some thermal insulation materials have their air permeability values declared, but it is more for wind protection and sound absorption calculations. There is no unified standard to calculate airtightness of a building envelope structure made up of different materials.

In this paper air leakage through various samples of masonry walls with insulation of different air permeability rock wool boards was investigated. One of the main purposes of this research is to analyse possibility to calculate air permeability of the completed wall having measured specific air flow resistances of every component of the wall. This could help to create more versatile airtightness prediction tool for composite structures based on laboratory measurements data.

\section{STRATEGY, METHODS AND MATERIALS USED IN INVESTIGATION}

\subsection{Main steps of investigation strategy for prediction of air tightness for thermally insulated walls structures with block masonry}

As mentioned in introduction, the most accurate method to predict air tightness of any structures is to measure their samples in laboratories. That is quite simple for any lightweight, homogenous constructions (insulation boards, prefabricated panels), but it is complicated to measure masonry wall in laboratory conditions because of its weight, dimensions and much work required for the specimen preparation. As a result, a simplified plan was created for this study to get more data from various masonry blocks wall samples at a lower cost. Stages of the study:

- Research of possibilities to replace masonry of various blocks with drilled wood fiber cement boards in the measurements of air permeability of wall samples;

- Laboratory measurements of air permeability of thermal insulation and wind protection boards used in research;

- Prediction by calculation of airtightness of wall samples using air permeability measurements data of wall components;

- Laboratory measurements of air permeability of modelled wall samples;

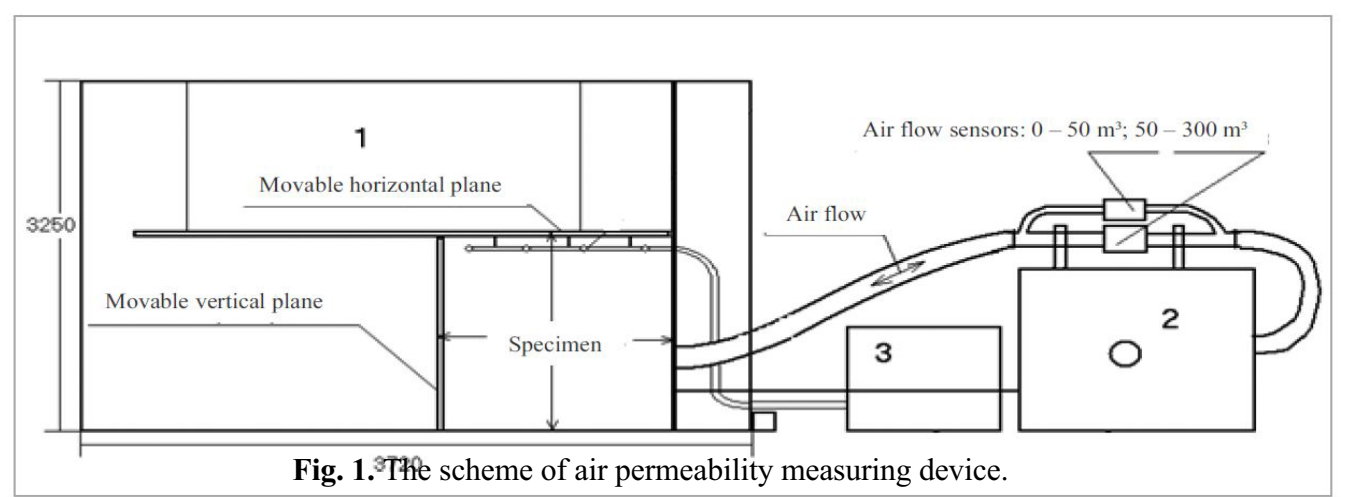




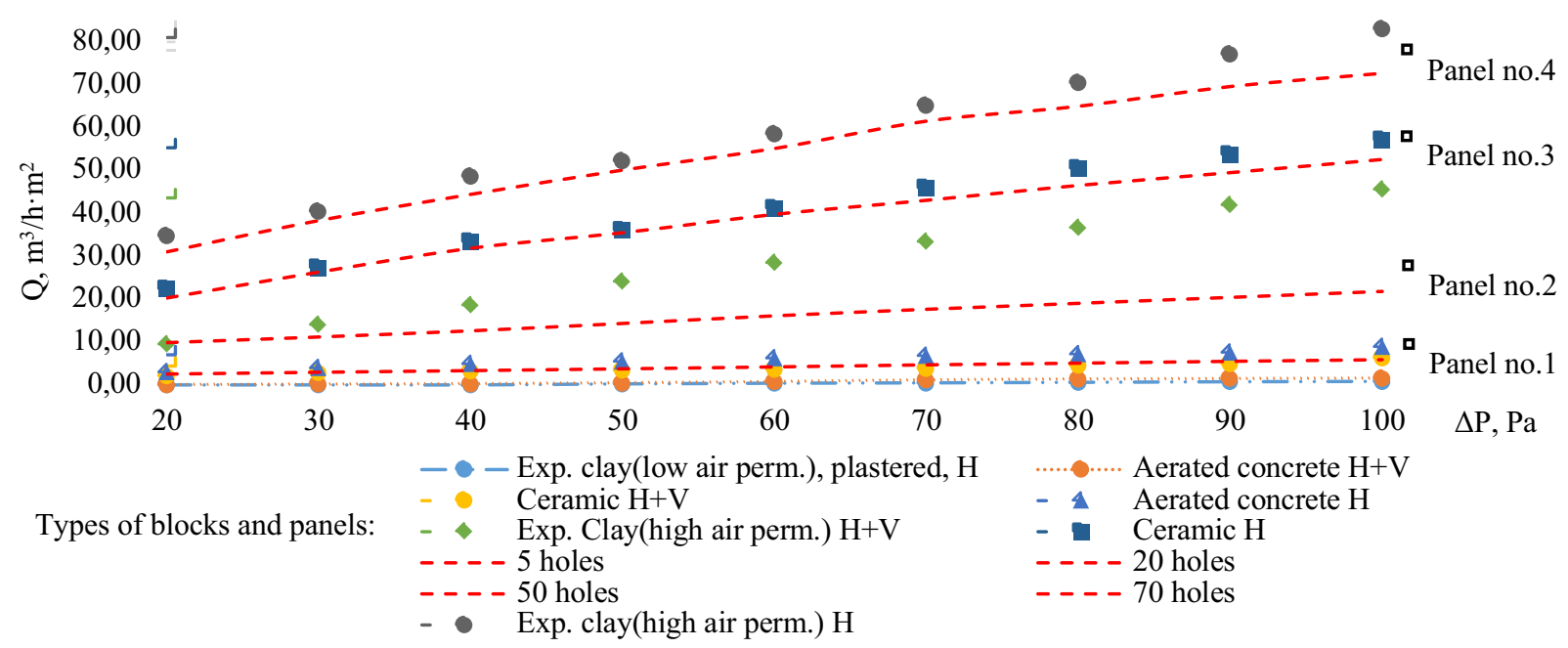

Fig. 2. Air permeability measurement results of various block masonry wall samples and drilled wood fiber cement boards.

- Comparison of calculated and measured results and evaluation of the suitability of calculation method for prediction of the airtightness of thermally insulated masonry blocks wall.

\subsection{Equipment and methods for laboratory measurements}

Measurements of air permeability of block masonry wall samples, thermal insulation, wind protection boards and modelled insulated structures were made using "KS 3030/650PC" (Fig. 1) device. The prepared specimens were installed in the opening of test chamber and sealed. Measurements were done by supplying air into test chamber and creating pressure difference between inside and outside of the specimen. The airflow through specimen was measured and recorded. The pressure difference during the measurement was changed from 10 $\mathrm{Pa}$ to $100 \mathrm{~Pa}$, as it is specified in the blower door test standard EN ISO 9972:2015 for air tightness measurement of buildings.

\subsection{Materials, products and modelled wall samples used for investigations}

Four types of blocks were chosen for research: aerated concrete and ceramic blocks that had high result in airtightness, and two types of expanded clay blocks, that are not airtight, but their air permeability is different. Seven block masonry wall samples were made from these blocks, using different technology of masonry with different joint filling (Fig. 3). Aerated concrete, ceramic and higher air permeability expanded clay blocks masonry wall samples were of two types: H-only horizontal joints were filled, $\mathrm{H}+\mathrm{V}$ - horizontal and vertical joints were filled. Wall samples of lower air permeability expanded clay blocks were only with horizontal joints filling and their surface was plastered. The types of blocks and their joints filling technology constructing masonry are shown in table 1 .
Table 1. Types of blocks and their joints filling technology.

\begin{tabular}{|c|c|c|c|}
\hline Blocks & $\begin{array}{c}\text { Horizontal } \\
\text { joints }\end{array}$ & $\begin{array}{c}\text { Vertical } \\
\text { joints }\end{array}$ & $\begin{array}{c}\text { Surface } \\
\text { plastering }\end{array}$ \\
\hline \multirow{2}{*}{ Aerated concrete } & Filled & - & - \\
\hline & Filled & Filled & - \\
\hline \multirow{2}{*}{ Ceramic } & Filled & - & - \\
\hline & Filled & Filled & - \\
\hline \multirow{2}{*}{$\begin{array}{l}\text { E. clay (high air } \\
\text { permeability) }\end{array}$} & Filled & - & - \\
\hline & Filled & Filled & - \\
\hline $\begin{array}{c}\text { E. clay (low air } \\
\text { permeability) }\end{array}$ & Filled & - & Yes \\
\hline
\end{tabular}

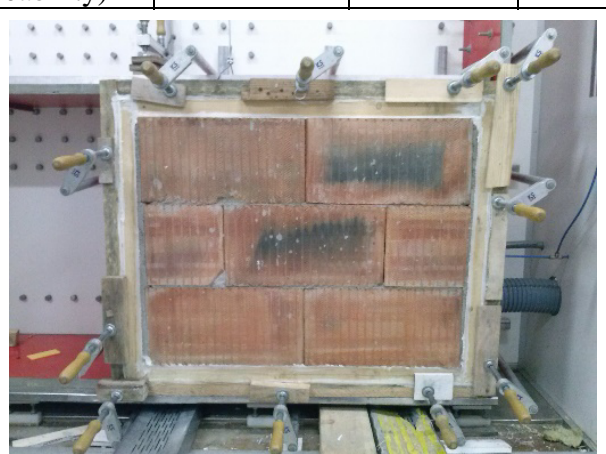

Fig. 3. Specimen of ceramic blocks masonry filled with horizontal joints mounted into air permeability measuring device.

Due to the high weight and thickness of the specimens and the complicated installation of completed insulated wall samples into test device, it was decided to replace the block masonry with perforated wood fiber cement board, (thickness of $8 \mathrm{~mm}$ ) with drilled holes of $5 \mathrm{~mm}$ diameter to simulate air paths through cracks in joints between blocks masonry. Number of holes was calculated considering results of air permeability measurements of block masonry wall samples. Numbers were given to panels with different number of holes: panel no.1 -5 , panel no. $2-20$, panel no. $3-50$ and panel no. $4-70$ holes. Rock wool boards with air permeability coefficient of $49 \cdot 10^{-6} \mathrm{~m} / \mathrm{m} \cdot \mathrm{s} \cdot \mathrm{Pa}$ were used for thermal insulation layer of masonry wall. Thermal insulation layer was created from 1 or 2 rock wool boards of $10 \mathrm{~cm}$ thickness. Wind protection layer was made from $2 \mathrm{~cm}$ thickness rock wool 
board (air permeability coefficient $9,4 \cdot 10^{-6} \mathrm{~m} / \mathrm{m} \cdot \mathrm{s} \cdot \mathrm{pa}$ ) or $5 \mathrm{~cm}$ thickness rock wool board (air permeability coefficient $\left.30,6 \cdot 10^{-6} \mathrm{~m}^{3} / \mathrm{m} \cdot \mathrm{s} \cdot \mathrm{Pa}\right)$.

The following wall constructions were modelled for every block masonry simulating panel with different number of drilled holes:

- Panel + rock wool $10 \mathrm{~cm}$;

- $\quad$ Panel + rock wool 2 x $10 \mathrm{~cm}$;

- $\quad$ Panel + rock wool $10 \mathrm{~cm}+$ rock wool wind protection $5 \mathrm{~cm}$;

- Panel + rock wool $10 \mathrm{~cm}+$ rock wool wind protection $2 \mathrm{~cm}$;

- $\quad$ Panel + rock wool 2 x $10 \mathrm{~cm}+$ rock wool wind protection $2 \mathrm{~cm}$;

Modelled wall samples were installed into wooden frames, sealed and then fixed in the air permeability measurement device (Fig. 4).

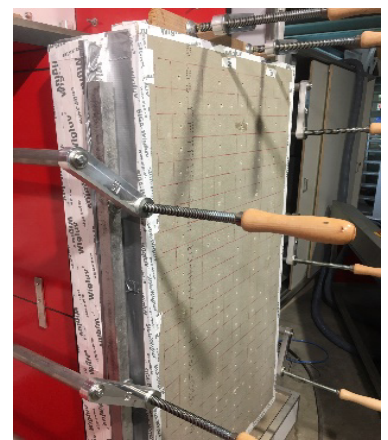

Fig. 4. Wall sample installed into test device: drilled wood fiber cement board + insulation in wooden frame.

\section{Results}

\subsection{Tests for validation of use of drilled wood fiber cement boards instead of block masonry in insulated wall samples for air permeability measurements.}

Laboratory measurement results of air permeability of various block masonry wall samples and wood fiber cement boards with drilled holes are shown in Fig. 2.

All types of masonry can be divided into 4 groups by results of measured air permeability. Aerated concrete and ceramic blocks masonry wall samples with filled horizontal and vertical joints, and silicate blocks masonry wall sample with filled only horizontal joints had the lowest air permeability results. Masonry of lower air permeability expanded clay with filled horizontal joints and plastered surface can be added to this group of specimens. All these specimens will be replaced with panel No. 1 with 5 drilled holes, which area is $1,36 \mathrm{~cm}^{2} / \mathrm{m}^{2}$ of panel area. Higher air permeability was fixed when masonry of expanded clay with filled horizontal and vertical joints were measured. This kind of block masonry is exceptional because during the test, air is moving through many small porous in block, where air permeability dependency on pressure difference is not linear. This kind of block masonry was replaced with panel No. 2 with 20 drilled holes, which area is 5,45 $\mathrm{cm}^{2} / \mathrm{m}^{2}$ of panel area. Air permeability measurement results of panel No. 2 matches similar results of blocks masonry, when pressure difference is lower. Ceramic blocks masonry wall sample with filled horizontal joints is assigned for the third group. Precision of ceramic blocks dimensions are quite lower than of aerated concrete blocks, therefore, additional cracks in vertical filling appears that make the masonry leakier. Masonry panel No. 3 with 50 drilled holes, which area is 13,63 $\mathrm{cm}^{2} / \mathrm{m}^{2}$ of panel area was chosen for replacement of this group of blocks. Expanded clay without vertical joints filling was the leakiest. Air leaks through the block and through vertical joint. Panel No. 4 with 70 drilled holes, which area is $19,08 \mathrm{~cm}^{2} / \mathrm{m}^{2}$ of panel area was chosen for replacement of this kind of block masonry. As it can be seen from Fig. 2, air permeability of this panel is close to the permeability of the block masonry over the whole range of pressure differences.

\subsection{Laboratory measurements of air permeability of thermal insulation and wind protection rock wool boards used in research}

Relations between measured air permeability and pressure difference of $10 \mathrm{~cm}$ thickness rock wool thermal insulation board, double $(10+10 \mathrm{~cm})$ boards, $2 \mathrm{~cm}$ thickness and $5 \mathrm{~cm}$ thickness of different air permeability wind protection rock wool boards are presented in Fig. 5.

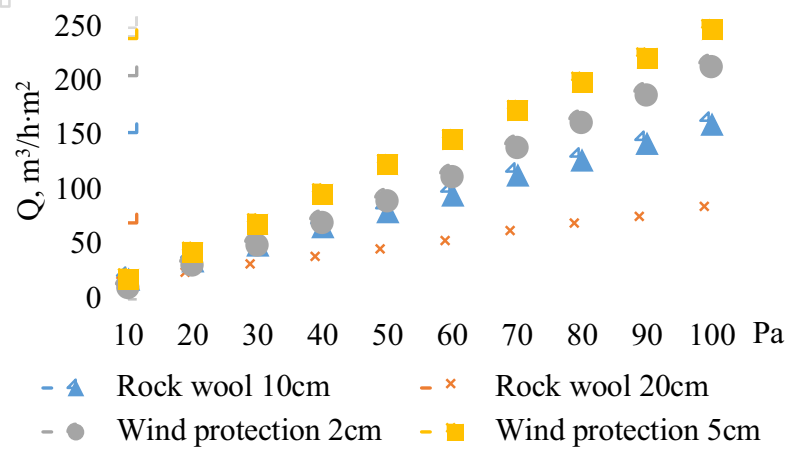

Fig. 5. Measured air permeability of different type of rock wool thermal insulation and wind protection boards.

3.3. Prediction of air permeability of wall samples using air permeability measurement data of wall constituting elements

Using measured air permeability of rock wool thermal insulation and wind protection boards and drilled wood fiber cement boards, which simulates different block masonry samples, specific air resistance is calculated for every component of insulated wall samples at air pressure difference of $50 \mathrm{~Pa}$, by (1):

$$
R_{S}=\frac{\Delta p}{q_{v} \cdot A}
$$

where

$\Delta \mathrm{p}$ is the air pressure difference, $\mathrm{Pa}$;

$\mathrm{q}_{\mathrm{v}}$ is the airflow through the specimen, $\mathrm{m}^{3} / \mathrm{h}$; A is area of the specimen, $\mathrm{m}^{2}$. 
The specific air resistances of perforated boards and rock wool materials are presented in table 2 .

Table 2. The specific air resistances of materials used in study.

\begin{tabular}{|l|c|}
\hline Name of the material & Rs \\
\hline Panel no. 1 & 13,33 \\
\hline Panel no. 2 & 3,49 \\
\hline Panel no. 3 & 1,41 \\
\hline Panel no. 4 & 1,00 \\
\hline Insulation rock wool $10 \mathrm{~cm}$ & 0,61 \\
\hline Wind protection rock wool 5cm & 0,16 \\
\hline Wind protection rock wool $2 \mathrm{~cm}$ & 0,22 \\
\hline
\end{tabular}

After determination of specific air resistance of every component of the wall sample, the specific air resistance of whole wall sample was calculated summing specific air flow resistances by equation (2):

$$
\mathrm{R}_{\mathrm{S}, \mathrm{sum}}=\mathrm{R}_{\mathrm{S} 1}+\mathrm{R}_{\mathrm{s} 2} \ldots+\mathrm{R}_{\mathrm{Sn}}
$$

Using calculated specific air resistance of wall sample, air permeability $50 \mathrm{~Pa}$ air pressure difference of this structure were calculated by (3):

$$
Q=\frac{\Delta p}{R_{S, \text { sum }}}
$$

Calculated specific air resistance of various constructions wall samples at pressure difference of $50 \mathrm{~Pa}$ are shown in Fig. 6.

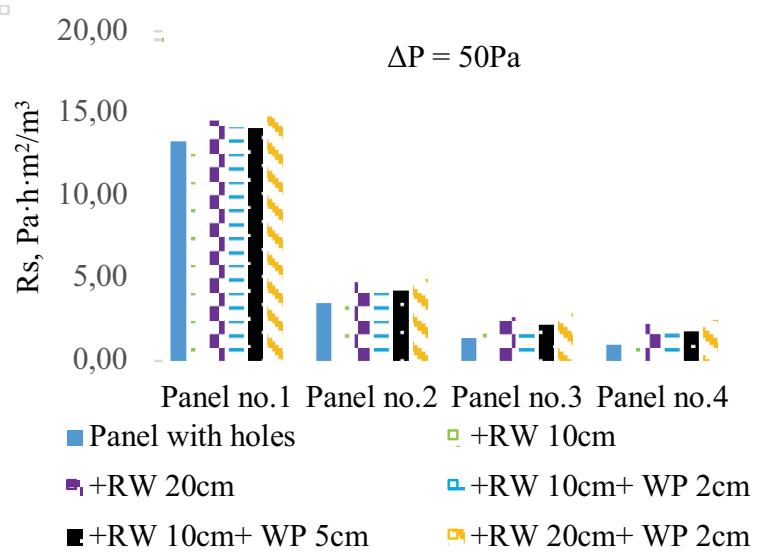

Fig. 6. Air flow resistances of 4 different panels with added thermal insulation and wind protection boards. (RW-rock wool thermal insulation, WP-wind protection).

The results of the calculations showed that installation of thermal insulation and wind protection layers of the walls significantly reduces the air permeability of the whole wall only when the air permeability of the masonry layer is low. In order to check reliability of the calculation results, measurements of simulated structures were made in a laboratory testing device.

\subsection{Laboratory measurements of air permeability of modelled wall samples}

$$
\begin{aligned}
& 6,000 \\
& 5,000 \\
& \text { Panel no. } 1
\end{aligned}
$$

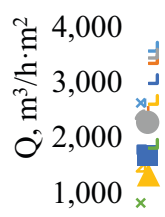

$$
\begin{aligned}
& 0,000 \\
& 20 \\
& \sum_{x}^{x} \\
& \frac{1}{x} \\
& -\infty \text { Panel with holes } \quad-\lrcorner \quad+\mathrm{RW} 10 \mathrm{~cm} \\
& \text { - +RW 20cm - } 1 \text { +RW } 10 \mathrm{~cm}+\mathrm{WP} 5 \mathrm{~cm} \\
& \text { - +RW } 10 \mathrm{~cm}+\mathrm{WP} 2 \mathrm{~cm} \mathrm{-} \quad \text { +RW } 20 \mathrm{~cm}+\mathrm{WP} 2 \mathrm{~cm}
\end{aligned}
$$

Fig. 7. Panel no. 1: air permeability dependence on pressure difference when various insulation variants applied.

Panels with drilled holes were mounted into wooden frame together with rock wool thermal insulation and wind protection boards. Air permeability was measured by changing pressure difference from $20 \mathrm{~Pa}$ to $50 \mathrm{~Pa}$. Air permeability dependence on pressure difference graph was drawn for every case.

For a more convenient comparison of results, the air permeability dependence on air pressure difference of panels with the same number of holes drilled is presented in one figure.

As it can be seen from results, rock wool thermal insulation boards make very low impact on air permeability of modelled construction in interval of pressure difference from $20 \mathrm{~Pa}$ to $50 \mathrm{~Pa}$. More impact on air permeability was noticed when wind protection boards made from rock wool were used. Their impact on air permeability of the whole construction is in proportion with their own air permeability. Thickening thermal insulation, when wind protection board are added, makes air permeability of the whole construction lower. Comparison of measured and calculated air permeability of different wall samples ant their matching tendencies are presented in Fig. 7.

Air permeability measurement results of construction with panel No. 2 are shown in Fig. 8.

$$
20,000
$$

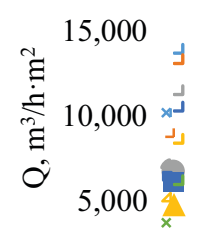

$$
\text { Panel no. } 2
$$

$$
\begin{aligned}
& 0,000 \\
& 20 \\
& \text { - +RW } 20 \mathrm{~cm} \\
& \text { - +RW } 10 \mathrm{~cm}+\mathrm{WP} 2 \mathrm{~cm}
\end{aligned}
$$

Fig. 8. Panel no. 2: air permeability dependence on pressure difference when various insulation variants applied.

All the results show bigger air permeability since panel No. 2 is less airtight than panel No. 1 that was used 
before. As it can be seen from Fig. 8, thicker thermal rock wool layer used without wind protection boards has bigger impact on reduction of ait permeability. Thicker thermal rock wool layer and lower air permeability of wind protection layer shows lowest air permeability results of the whole structure.

50,000

Panel no. 3
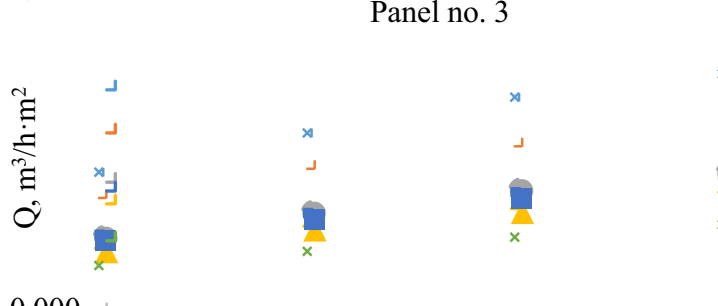

$$
\begin{aligned}
& 20 \\
& 30 \\
& \Delta \mathrm{P}, \mathrm{Pa} 40 \\
& -\lrcorner \quad+\mathrm{RW} 10 \mathrm{~cm} \\
& -\rtimes \quad \text { Panel with holes } \\
& \text { - } \quad+\text { RW } 20 \mathrm{~cm} \\
& \text { - } 1 \quad+\text { RW } 10 \mathrm{~cm}+\mathrm{WP} 5 \mathrm{~cm} \\
& \text { - +RW } 10 \mathrm{~cm}+\mathrm{WP} 2 \mathrm{~cm} \\
& { }_{-} \times \quad+\mathrm{RW} 20 \mathrm{~cm}+\mathrm{WP} 2 \mathrm{~cm}
\end{aligned}
$$

Fig. 9. Panel no. 3: air permeability dependence on pressure difference when various insulation variants applied.

Air permeability measurement results of wall sample with panel No. 3 are show in Fig. 9. In this case, thermal insulation layer is becoming more significant as air permeability of panel No. 3 is less airtight than other two used before. Air permeability of the whole construction decreases almost twice only by doubling construction thermal layer from $10 \mathrm{~cm}$ to $20 \mathrm{~cm}$. Even though wind protection layer impact is less significant but its installation can reduce air permeability of the whole construction by almost 3 times.

Air permeability measurement results of construction with panel No. 4 are show in Fig. 10.

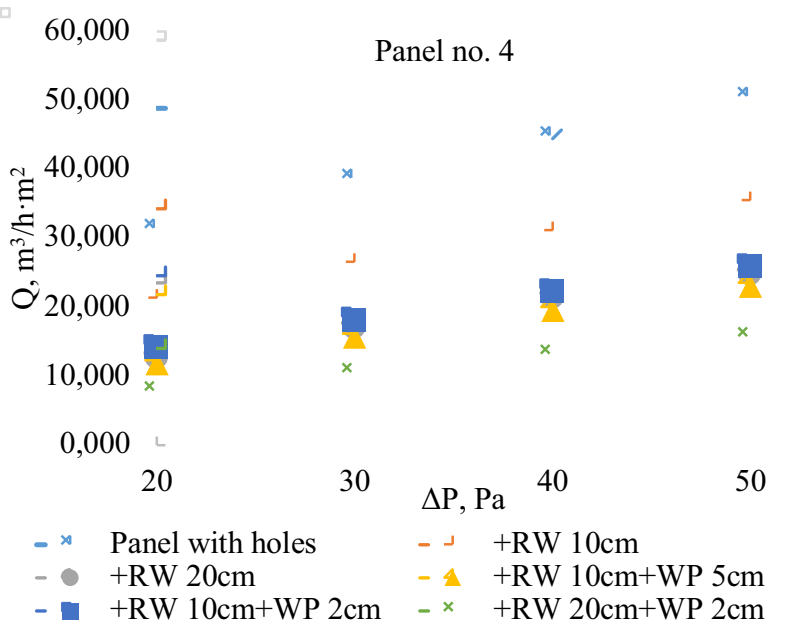

Fig. 10. Panel no. 4: air permeability dependence on pressure difference when various insulation variants applied.

In this case, when the panel No.4 with the highest air permeability is installed, higher air permeability of the whole structure is gained, the impact of thermal insulation and wind protection layers to constructions air permeability is even more significant. Although it is obvious that priority must be given to air barriers when seeking airtightness of the insulated wall. Even though thermal and wind protection layers can decrease air permeability of the wall segment, but it will never make it airtight.

\subsection{Comparison of calculated and measured air permeability of construction}

After air permeability of modeled wall samples were measured and calculated, air permeability of wall samples at $50 \mathrm{~Pa}$ air pressure difference were compared. Results are shown in table 3 .

After calculations and measurements of air permeability of wall samples insulated with two types rock wool thermal insulation and wind protection boards, which thickness was less than $150 \mathrm{~mm}$, results of calculated and measured values differ about $12 \%$. Measured and calculated air permeability values differs about $15 \%$, when the same wall sample insulated with one type of rock wool thermal insulation boards.

The measured and calculated results of air permeability of wall samples insulated with two types rock wool thermal insulation and wind protection boards, which thickness was $150 \mathrm{~mm}$ and more, results differ from $22 \%$ to $69 \%$.

Table 3. Calculated and measured values of construction air permeability at $50 \mathrm{~Pa}$ pressure difference.

\begin{tabular}{|c|c|c|c|c|c|}
\hline $\begin{array}{c}\text { Panel, } \\
\text { No. }\end{array}$ & $\begin{array}{c}\text { Insulation } \\
\text { layer, cm }\end{array}$ & $\begin{array}{c}\text { Wind } \\
\text { protection } \\
\text { layer, cm }\end{array}$ & $\begin{array}{c}\text { Q } \\
\text { calculated, } \\
\mathrm{m}^{3} / \mathrm{h}^{2}\end{array}$ & $\begin{array}{c}\mathrm{Q} \\
\text { measured, } \\
\mathrm{m}^{3} / \mathrm{h} \cdot \mathrm{m}^{2}\end{array}$ & Diff., \% \\
\hline \multirow{4}{*}{1} & 10 & - & 3,58 & 3,53 & $-1,62$ \\
\cline { 2 - 6 } & 20 & - & 3,43 & 3,63 & $+5,5$ \\
\cline { 2 - 6 } & 10 & 5 & 3,54 & 2,79 & $-26,94$ \\
\cline { 2 - 6 } & 10 & 2 & 3,53 & 3,17 & $-11,43$ \\
\cline { 2 - 6 } & 20 & 2 & 3,37 & 2 & $-68,71$ \\
\hline \multirow{4}{*}{2} & 10 & - & 12,19 & 13,72 & $+11,19$ \\
\cline { 2 - 6 } & 20 & - & 10,52 & 11,89 & $+11,48$ \\
\cline { 2 - 6 } & 10 & 5 & 11,72 & 9,01 & $-30,07$ \\
\cline { 2 - 6 } & 10 & 2 & 11,56 & 10,92 & $-5,91$ \\
\hline \multirow{4}{*}{3} & 20 & 2 & 10,05 & 6,57 & $-53,05$ \\
\cline { 2 - 6 } & 10 & - & 24,71 & 28,85 & $+14,34$ \\
\cline { 2 - 6 } & 20 & - & 18,71 & 21,25 & $+11,93$ \\
\cline { 2 - 6 } & 10 & 5 & 22,88 & 17,92 & $-27,71$ \\
\cline { 2 - 6 } & 10 & 2 & 22,27 & 19,89 & $-11,97$ \\
\hline \multirow{4}{*}{4} & 20 & 2 & 17,28 & 12,21 & $-41,54$ \\
\cline { 2 - 6 } & 10 & - & 31,02 & 35,54 & $+12,74$ \\
\cline { 2 - 6 } & 20 & - & 22,12 & 24,79 & $+10,78$ \\
\cline { 2 - 6 } & 10 & 5 & 28,19 & 23,1 & $-22,03$ \\
\cline { 2 - 6 } & 10 & 2 & 27,26 & 25,83 & $-5,53$ \\
\cline { 2 - 6 } & 20 & 2 & 20,14 & 15,29 & $-31,72$ \\
\hline
\end{tabular}

\section{Conclusions}

The conducted research is an initial attempt of development of wall air permeability prediction tool according to building component air permeability model. The results of experimental measurements and calculations revealed:

1. An analysis of the feasibility of replacing block masonry with perforated board in experimental research has shown sufficiently coinciding of air permeability test results. This amendment is proposed to use in further investigation for less complex 
installation of insulated wall samples into measurement device.

2. Analysis of air permeability calculation and measurement results of wall samples showed smaller differences in cases where the nature of air movement (laminar to turbulent) through a single material remains similar with the nature of air movement through the same material incorporated in the structure. This is typical of walls with a lower thickness of thermal insulation and of more air permeable wind barrier.

3. The different air permeability calculation and measurement results were obtained in cases where the air movement parameters through a single material and through the same material incorporated in the structure have changed. This is typical of walls with very different air permeability properties of components, especially at high thicknesses of air permeable thermal insulation products.

4. Studies have shown that the nature of air movement through a single layer may differ from that of air movement through the same product contained in a composite structure. The purpose of further research will be to find out the causes and circumstances of such changes.

\section{References}

1. J. Šadauskienè, L. Šeduikytè, V. Paukštys, K. Banionis, A. Gailius, Energy for Sustainable Develompent 32, 31-39 (2016)

2. T-O. Relander, S. Holos, J. V. Thue, Energy and Buildings 54, 444-452 (2012)

3. M. Prignon, G. V. Moeseke, Energy and Buildings 146, 87-97 (2017)

4. T-O. Relander, T. Kvande, J. V. Thue, Energy and Buildings 42, 684-694 (2010)

5. J. Hallik, H. Gustavson, T. Kalamees, Buildings 9, 172 (2019)

6. T. Kalamees, U. Alev, M. Parnalaas, Building and Environment 116, 121-129 (2017)

7. J. Langmans, T. Z. Desta, L. Alderweireldt, S. Roels, Int. journal of ventilation 16, 30-41 (2017)

8. H. Krstic, Ž. Koški, I. I. Otkovic, M. Španič, Energy and Buildings 84, 160-168 (2014)

9. H. Krstic, I. I. Otkovic, G. Todorovic, Energy procedia 78, 1525-1530 (2015)

10. H. Krstic, I. I. Otkovič, P. Kosinski, R. Wojcik, Energy and Buildings 133, 423-432 (2016) 